\title{
Sources of variation in attitudes and beliefs about federal rangeland management
}

\author{
MARK W. BRUNSON AND BRENT S. STEEL
}

Authors are assistant prafessor, Department of Forest Resources, Utah State University, Logan, Utah 843225215; and assistant professor, Department of Political Science, Washington State University, Vancouver, Wash. 98663.

Abstract

Successful managers of federal rangelands in the next century will have to implement politically supportable policies that address both forage and non-forage values. To do so will require an understanding of beliefs and attitudes across a wider spectrum of American society than the traditional range clientele. In 1993 a study was conducted to examine geographic variation in general public attitudes and beliefs about federal range management, and the linkage between general environmental values, attitudes toward federal range policy and management, and beliefs about environmental conditions on federal rangelands. While there was some evidence of an East-West dichotomy on range issues, greater support was found for a dichotomy between urban areas throughout the U.S. and rural regions where rangelands are important to local economies. Attitudes and beliefs about rangelands were typically rooted in simplistic, value-based ideas about the goodness or badness of range practices and conditions.

Key Words: attitudes, beliefs, survey, federal policy, environmental values.

Public concern about the natural environment and its management has increased in the past quarter-century (Dunlap 1992). Rangeland policy and practices increasingly come under public scrutiny, especially on federal lands. Yet little social-scientific research has examined the American public's attitudes toward range practices and policies, demands for rangeland uses, or beliefs about the quality of range environments. For citizens to make informed choices about the future of federal lands, they need help from range professionals who understand the nature and origins of the public's beliefs and attitudes-not simply among traditional grazing or hunting publics but across a much wider spectrum of society. A suc-

This research was supported by the Utah Agricultural Experiment Sation, Utah State University, Logan, Utah 84322-4810 (MacIntire-Stennis Project No. UTA700 ) with additional support from the Sustainable Forestry Program, Oregon State University; the Consortium for the Social Values of Natural Resources; and Washington State University-Vancouver. Approved as journal paper No. 4599.

Manuscript accepted 3 Mar. 1995. cessful manager of public rangelands in the coming decades must be able to translate public attitudes into supportable policies that address both forage and non-forage values.

Because traditional range uses occur mostly in the rural West, we might expect rural and western populations to be more supportive of current range policy than urban and eastern populations. However, previous research on environmental attitudes suggests that the picture may be more complicated than that. Attitudes toward natural resources gradually are shifting to an amenity-oriented view (Brown and Harris 1992), and this trend is more pronounced in cities and suburbs than in rural areas (Buttel 1987). Moreover, persons who hold generally environmentalist views may oppose environmentally motivated management actions that restrict their own personal choices (Noe and Hammitt 1992), and Western economic interests are more closely tied to range commodities. Environmental attitudes also are related to knowledge about the quality of those environments (Pierce et al. 1989), and such knowledge is likely to be greatest in the Intermountain West and Great Plains.

However, Gallup polls (e.g., Graham 1991) usually find litthe regional variation in environmental attitudes. Similarly, a forestry survey by Shindler et al. (1993) found relatively few differences in responses from Oregon and the nation as a whole. One reason may be that while natural resources are economically important in the West, the region is also highly urbanized (Brunson and Kennedy 1995). Traditional concepts of "rural" or "urban" are confounded as urbanites move to the rural West, usually because of region's amenities (Rudzitis and Johansen 1991; Rasker 1993). As a result, a rural environmentalist voice is emerging in debates over natural resource issues (Fortmann and Kusel 1990).

This paper examines how these various influences are linked to differences in attitudes and beliefs about federal rangelands and their management. It describes results of a 1993 study focusing on (a) differences in attitudes and beliefs about federal range management associated with the local or regional importance of rangelands, and (b) associations between overall environmental attitudes, attitudes toward federal range management, and beliefs about environmental conditions on federal rangelands. 


\section{Methods}

\section{Sampling}

Data come from 3 parallel surveys: 2 telephone surveys of randomly selected households, 1 conducted nationally and the other in Oregon; and a mail survey of residents of 17 Oregon counties where rangeland environments predominate and livestock grazing contributes significantly to local economies. Sample frames were provided by a national survey research firm which draws households at random from a data base of current telephone directories. There was no geographic stratification within samples. Dillman's (1978) total design method guided survey design and implementation. For the national survey, we contacted 2,000 households and completed 1,360 interviews, a $68 \%$ response rate. In the Oregon survey, we contacted 1,500 households and completed 1,003 interviews $(67 \%)$. Both telephone surveys were conducted in March-June 1993, using identical questionnaires. A mail survey, containing all questions from the telephone survey plus several others, was sent to 500 residents of eastern Oregon counties in September 1993. We received 280 usable responses and 64 other surveys were undeliverable, a $64 \%$ response rate.

Response rates are consistent with our previous mail and telephone surveys on environmental issues (e.g., Shindler et al. 1993), and were within Dillman's (1978) guidelines. Many persons who declined to respond said they had no opinion about rangelands or their management. Therefore results may tend to emphasize the views of those most likely to be concerned about rangeland policy.

\section{Survey Instrument}

Survey questions covered: (1) attitudes toward management of federal rangelands; (2) knowledge about the environmental condition of federal rangelands; (3) confidence in organizations and institutions involved in range management; (4) relative influence that different rangeland constituencies should have on policy development and implementation; and (5) attributes of respondents that could influence beliefs, including their overall attitudes toward the relationship between society and the natural environment as well as demographic characteristics. Many questions were adapted from a recent study of public attitudes about federal forest management in Oregon and in the U.S. (Shindler et al. 1993). The national survey and its implications are discussed further in Brunson and Steel (1994).

The primary attitude/belief measure was a series of questions asking people for their level of agreement with statements about rangelands and range management. For each question, respondents were asked to choose a response of 1 (strongly disagree), 2 (disagree), 3 (neutral), 4 (agree) or 5 (strongly agree). For statements about the environmental condition of rangelands, respondents could also choose a "don't know" response. No more than 4\% answered "don't know" to any single question. Data from "don't know" responses are excluded from analyses reported here.

Respondents were asked to give their views about "federal lands such as those managed by the Bureau of Land Management and the U.S. Forest Service," with particular attention to rangelands. To further clarify the attitude object, a definition of "rangeland" was given. Choosing a definition was problematic, as there are many such definitions and none is universally accepted (Holechek et al. 1989). To ensure a valid telephone survey, the definition could be no more complex than a single phrase. The phrase we chose was "places that have arid climates, where grassland or desert environments are more common than heavily forested ones (although forested areas may be present)." In the Oregon surveys, eastern Oregon was identified as an example of a range environment.

Table 1 lists the attitude and belief items specific to rangelands and their management. Six items were used to evaluate beliefs about the environmental condition of federal rangelands. Ten items were used to evaluate attitudes toward man-

Table 1. Statements used as attitude and belief items.

Attitude statements

The economic vitality of local communities should be given the highest priority when making decisions about federal rangelands.

Livestock grazing should be banned on federal rangelands.

More wilderness areas should be established on federal rangelands.

Livestock grazing should be permitted in rangeland wilderness areas.

Greater protection should be given to fish such as salmon in rangelands.

Greater efforts should be made to protect rare plant communities on federal rangelands.

Endangered species laws should be set aside to preserve ranching jobs. Federal rangeland management should emphasize livestock grazing.

Greater efforts should be given to protect wildlife on federal rangelands.

Ranchers should pay more than they do now to graze livestock on federal land.

\section{Belief statements}

Most federal rangelands are overgrazed by cattle and/or sheep.

Soil erosion is only a minor problem on federal rangelands.

Populations of most wildlife species on federal rangelands have remained constant or are increasing.

The quality of water from federal rangelands has decreased markedly in the past 50 years.

The extent of overgrazing on federal lands has decreased markedly in the past 50 years.

The loss of streamside vegetation is a serious problem on federal range lands.

agement of those lands. Shortened versions of these statements will be used in subsequent tables to describe the relationships between survey samples or attitude/belief items. An additional item provided further insight into range management attitudes. Respondents were asked which of 3 choices is "the proper model of management to follow on federal rangelands." Choices were: "agricultural, emphasizing the efficient production of forage to provide meat products for society"; "multiple benefits, emphasizing a long-term sustainable balance between human and ecological concerns"; and "preservation, emphasizing minimal alteration and interference in rangelands by humans."

\section{Analytical Methods}

Two comparative approaches were used: a simple EastWest comparison looked for regional differences in attitudes and beliefs; and a comparison across differing scales of analysis examined differences associated with a population's proximity (and presumed familiarity) with federal rangelands. For the first comparison, respondents from the national sample only were divided into 2 groups based on whether their 
Table 2. Factor analysis1 of general environmental attitude statements.

\begin{tabular}{|c|c|c|c|}
\hline Attitude statement & $\begin{array}{c}\text { Factor } 1 \\
\text { DOMINION }\end{array}$ & $\begin{array}{l}\text { Factor } 2 \\
\text { ETHICS }\end{array}$ & $\begin{array}{c}\text { Factor } 3 \\
\text { SCIENCE }\end{array}$ \\
\hline Plants and animuls exist primarily for human use & .8970 & -.0671 & .0154 \\
\hline Humankind was created to rule over the rest of nature & 8796 & -.0626 & -.0403 \\
\hline Humans and nature can live together in productive harmony & .2435 & .7470 & -.0732 \\
\hline The earth should have far fewer people on it & -.1663 & .1174 & .4810 \\
\hline $\begin{array}{l}\text { Technology will find a way of solving the problem of } \\
\text { shortages of natural resources }\end{array}$ & -.3446 & .2310 & -4440 \\
\hline People would be better off if they lived without so much technology & -.0096 & .2122 & .7521 \\
\hline Technical \& scientific experts are usually biased & .2769 & -.0962 & .7250 \\
\hline
\end{tabular}

${ }^{3}$ Varımax rotation. Eigenvalues: 2.2787 : 1.6194; 1.4386. Pct. of variance explained: $59.3 \%$.

region contains rangelands or large amounts of federal land. The rangeland group included the 11 western states plus Alaska, Hawaii, Kansas, Nebraska, North and South Dakota. T-tests were used to compare mean responses to attitude and belief items, and chi-square tests were performed on the categorical question. An alpha of .05 was used to measure significant differences.

The second comparison was made between each of the 3 samples, using one-way analysis of variance (ANOVA) to compare for differences in mean responses to attitude and belief items. This approach was chosen because it allowed us to compare attitudes in a Western state that has significant acreages of federal rangelands with those of the nation as a whole, while simultaneously comparing attitudes in grazingdependent portions of a typically urbanized Western state with those of the state as a whole. In so doing, we also addressed a thcoretical issue of how the scale at which political opinions are measured may reflect differences in beliefs about the attitudes within a political constituency. The eastern Oregon sample provided an analysis at the level of the U.S. House of Representatives level, while the Oregon sample offered an analysis at the U.S. Senate level, and the national sample an analysis at the Executive Branch level.

Pearson product-moment correlations were used to test for associations between beliefs about environmental conditions, attitudes toward specific range management issues, and general environmental attitudes. All 3 samples could be combined $(\mathrm{N}=2,643)$ for this analysis, since we were looking only for associations within the individual response patterns of each study participant. Because Pearson correlations are a powerful test and significance is dependent upon sample size, values for $R$ as low as .067 may be judged significant at the .05 level when a sample surpasses 2,500 cases-even though such an association would explain less than one-half of $1 \%$ of the total variance in responses. Accordingly we chose a standard based on politically practical significance rather than statistical significance: correlations are judged as significant only when more than $10 \%$ of the total variance is explained $(\mathrm{R}=.316 ; \alpha<.001)$.

Three variables are used to describe overall environmental attitudes. These were obtained by multivariate analysis of a nine-item Likert type scale partially based on the New
Environmental Paradigm scale of Dunlap and Van Liere (1978) and used in recent research on public attitudes toward federal forest management (Shindler et al. 1993; Steel et al. 1994). The nine statements described attitudes toward the relationship between society and natural resources, natural resource scientists, or nature itself. Factor analysis (varimax rotation) of the combined samples revealed a 3 -dimensional attitude construct (Table 2). These dimensions can be characterized as describing: attitudes concerning human domination of nature (hereafter referred to as DOMINION); attitudes concerning the ethical relationship between society and nature (ETHICS); and attitudes concerning the extent to which science and technology have exceeded natural limits (SCIENCE).

\section{Results and Discussion}

\section{Regional Comparisons}

In general, attitudes in the national and Oregon samples reflected public preferences for a more preservationist, less livestock-oriented approach to federal rangeland management. The eastern Oregon sample was more favorable toward traditional uses such as livestock grazing and hunting. Comparisons between the rangeland (western) and non-rangeland regions (Table 3 ) found significant differences for 7 of the 10 attitude items. Residents of the rangeland region were more likely to agree that grazing should be allowed in wilderness and that endangered species laws should be set aside to protect ranching jobs. They were less likely to believe more wilderness is needed, grazing should be banned, ranchers should pay higher grazing fees, or greater efforts are needed to protect fish and rare plants. However, even where statistically significant differences were found, there was no case in which one region supported a statement while the other opposed it. A significant difference was found in responses to the question about a proper range management model (Table 4): westerners were more likely to support a preservation model of range management than were easterners.

Regional differences were found for 2 of the 6 belief statements (Table 3 ) about environmental condition of rangelands. Residents of the non-rangeland region were more likely to 
Table 3. Differences in attitudes and beliefs about federal rangelands and their management between regions and politically relevant scales of range dependency.

\begin{tabular}{|c|c|c|c|c|c|}
\hline \multirow[b]{2}{*}{ Altitude items } & \multicolumn{2}{|c|}{ REGION } & \multicolumn{3}{|c|}{ SCALE OF DEPENDENCY } \\
\hline & East $^{1}$ & West & U.S. & Ore. & E. Ore. \\
\hline Priority to local economy & 3.05 & 3.01 & $3.04 a$ & $3.10 \mathrm{a}$ & $3.63 b$ \\
\hline Ban livestock grazing & 3.24 & $3.06 * *$ & $3.17 \mathrm{~b}$ & $3.16 b$ & $1.87 \mathrm{a}$ \\
\hline Allow wilderness grazing & 2.53 & $2.78^{* *}$ & $2.62 \mathrm{a}$ & $2.62 \mathrm{a}$ & $3.23 \mathrm{~b}$ \\
\hline More protection for fish & 4.18 & $3.81^{* * * *}$ & $4.04 c$ & $3.51 \mathrm{~b}$ & $3.04 \mathrm{a}$ \\
\hline More protection for rare plants & 4.13 & $3.91 \%$ & $4.05 c$ & $3.37 \mathrm{~b}$ & $2.87 \mathrm{a}$ \\
\hline More protection for wildlife & 4.40 & 4.40 & $4.40 c$ & $4.22 b$ & $3.24 \mathrm{a}$ \\
\hline Ranchers should pay more & 3.93 & $3.69 * *$ & $3.84 \mathrm{c}$ & $3.25 b$ & $3.00 \mathrm{a}$ \\
\hline \multicolumn{6}{|l|}{ Beliefs } \\
\hline Most rangelands are overgrazed & 3.46 & 3.58 & $3.51 \mathrm{c}$ & $3.27 \mathrm{~b}$ & $2.75 \mathrm{a}$ \\
\hline Soil erosion is minor problem & 2.43 & 2.32 & $2.39 a$ & $2.59 \mathrm{~b}$ & $3.05 \mathrm{c}$ \\
\hline
\end{tabular}

T-texts for differences in mean Likert scale responses; signilicance shown by $*<.05, * *<.01$,

to $<001$ : scale values range from 1 (strongly disagree) to 5 (strongly agree).

ab Different superscript letters indicate statistical differences in means ( $F$-test, $p<.0001$ )

believe that riparian vegetation loss is a serious problem, and that the extent of overgrazing on federal rangelands has decreased.

Generally the results of the regional attitude comparison are in predictable directions, with the western states showing greater preference for management that stresses traditional or utilitarian uses and less preference for protective management. However, differences in support were slight, and never did one region support a policy that the other rejected. Similarly, results of the belief comparison suggest that the public in western states is no more or less aware of the environmental condition of rangelands than easterners. Responses reflect a generalized belief that federal rangelands have suffered environmental damage, and this pessimism is no less in the West than in the East.

Two results were in directions that were not predicted. Westerners were more likely to support a preservationist approach to range management, and they were less likely to know that the extent of overgrazing in their region has decreased over the past half-century. A potential explanation for this, and for the relative lack of regional variation overall, is that most residents of the West live within 100 miles of the Pacific Ocean, where amenity uses of public lands are important but grazing uses are not.

\section{Comparisons Across Politically Relevant Scales of Grazing-dependency}

The eastern Oregon sample differed from the Oregon statewide and national samples on all 18 attitude and belief items (Table 3). F-tests for differences in means were significant at the .0001 level for all 18 comparisons. Responses from the Oregon sample were generally between those of the national and eastern Oregon samples, suggesting that support for the more environmentalist positions of the national group was moderated somewhat by closer proximity to rangelands and grazing-dependent communities. However, Oregonians generally responded more like the national public than like a grazing-dependent public: the average difference in means between Oregon and the nation was 0.37 , while the average difference in means between Oregon as a whole and its eastern counties was 0.51 .

In all cases, residents of the grazing-dependent region of eastern Oregon were more supportive than the national or statewide samples of statements advocating traditional or utilitarian uses, and less supportive of statements urging greater protection of non-forage resources. For 4 items (ban livestock grazing, more wilderness areas, protect rare plants, higher grazing fees) the eastern Oregon sample was the only one whose mean response was at or below the neutral midpoint, showing that policies supported in national or statewide polls may not be favored in grazing-dependent communities. For 2 other items (allow wilderness grazing, emphasize livestock) the eastern Oregon sample was the only one with a mean response above neutral, showing that locally favored actions lacked national support.

The Oregon and national samples differed on 7 of the 10 attitude items. The gap was largest on issues of wilderness designation, rare plant protection, endangered species laws, and grazing fees. Partly this may be a side effect of statewide concern about economic effects of species-protection laws on

Table 4. Differences in preferences for range management model.

\begin{tabular}{|c|c|c|c|c|c|}
\hline \multirow[b]{2}{*}{ Management model } & \multicolumn{2}{|c|}{ REGION $^{\prime}$} & \multicolumn{3}{|c|}{ SCALE OF DEPENDENCY ${ }^{2}$} \\
\hline & East & West & U.S. & Ore. & E. Ore. \\
\hline & - & . & $(\mathscr{C})$ & & $\cdots$ \\
\hline Agricultural & 11.1 & 12.6 & 11.6 & 15.5 & 14.3 \\
\hline Multiple benefits & 69.4 & 58.4 & 65.2 & 58.7 & 75.3 \\
\hline Preservation & 19.6 & 29.0 & 23.1 & 21.8 & 10.4 \\
\hline
\end{tabular}

$1 \chi^{2}=17.8, p<.001$

$2 \chi^{2}=37.0 \quad p<001$ 
Table 5. Correlations between general environmental attitudes and attitudes toward range management practices or beliefs about range environmental condition.

\begin{tabular}{lccc}
\hline & $\ldots \ldots-$ General attitudes-.--- & $\ldots$ & \\
Attitude items & DOMINION & ETHICS & SCIENCE \\
\hline Priority to local economy & $.352^{* 2}$ & -.088 & -.087 \\
Ban livestock grazing & -.166 & .199 & .040 \\
More wilderness areas & $-.365^{*}$ & $.381^{*}$ & .135 \\
Allow wilderness grazing & $.372^{*}$ & -.195 & -.096 \\
More protection for fish & $-.349^{*}$ & $.442^{*}$ & .132 \\
Mlore protection for rare plants & $-.362^{*}$ & $.413^{*}$ & .092 \\
Repeal endangered species laws & $.428^{*}$ & -.246 & -.066 \\
Emphasize livestock grazing & $.408^{*}$ & -.124 & -.067 \\
More protection for wildlife & -.248 & $.450^{*}$ & .172 \\
Ranchers should pay more & -.270 & $.358^{*}$ & .134 \\
Belief items & & & \\
Most rangelands are overgrazed & $-.416^{*}$ & $.401^{*}$ & .152 \\
Soil erosion is minor problem & $.532^{*}$ & -.173 & -.043 \\
Wildlife populations increasing & $.454^{*}$ & -.224 & -.070 \\
Water quality markedly worse & -.247 & $.434^{*}$ & .171 \\
Overgrazing is down markedly & $.323^{*}$ & -.133 & -.047 \\
Serious riparian vegetation loss & .157 & .121 & -.163 \\
\hline
\end{tabular}

Dimensions derived from factor analysis of a general attitude scale (Table 2)

${ }^{2}$ Asterisk indicate's correlations explaining $>10 \%$ of variance in responses ( $R>316$ ).

the state's timber industry. There was no difference in attitudes toward giving priority to local communities, banning grazing on federal lands, or wilderness grazing. In only 1 case did the national public support or oppose a statement when the Oregon public did not: Oregonians were neutral on the subject of emphasizing livestock grazing on federal rangelands, while the national public opposed such an approach.

The 3 samples also differed significantly in their preferences for a range management model (Table 4 ). The most prominent source of variation in responses was that residents of eastern Oregon were less than half as likely as the other two groups to support a preservationist model. The eastern Oregon population was the most supportive of a multiple benefits approach like that of the U.S. Forest Service and Bureau of Land Management.

Responses to the belief items (Table 3) show that eastern Oregon residents differed from the other 2 samples on all 6 beliefs, while the Oregon and national samples differed on 4 of the 6. Eastern Oregon responses tended to be non-committal, never straying far from the neutral point. For 4 of the 6 items, the eastern Oregon sample gave slightly positive responses while the other 2 groups held negative beliefs about rangeland environments. Differences between the Oregon and national samples were much smaller $(\bar{x}=.17)$ than those between the Oregon statewide and eastern Oregon samples $(\bar{x}=.78)$.

\section{Attitude/Belief Correlations}

Correlations between general environmental attitudes and specific attitudes or beliefs are shown in Table 5 . Seven of the 10 specific attitudes are correlated with the DOMINION attitude scale, and 5 are correlated with the ETHICS scale. None of the specific attitudes are correlated with the SCIENCE scale. Only I specific attitude item (ban livestock grazing) is not strongly correlated with any of the 3 general attitude scales. The DOMINION scale is strongly correlated with 4 of the 6 belief items, the ETHICS scale with 2 items, and the SCIENCE scale with none of the items. Belief in the seriousness of riparian vegetation loss is the only one not strongly correlated with at least 1 general scale.

Attitudes and beliefs ahout rangelands both appear to be strongly associated with general attitudes toward human dominion over nature. People who believe that the world and its resources were created for human use are more likely to support traditional uses of range and more likely to believe that those uses have not had a deleterious effect on public rangelands (or that such effects are being ameliorated without abandoning traditional uses). Specific attitudes and beliefs are also related, although less definitively, to beliefs about the ethically proper relationship between humans and nature. People who value a harmonious relationship between nature and society are more likely to favor protective actions and an increase in grazing fees, and morc likely to believe most rangelands are overgrazed and most streams polluted. However, there is not as strong a relationship between protective attitudes or pessimistic beliefs and the general attitude that human technologies have overstepped their bounds. This may be because the public blames range environmental problems on livestock grazing, a "low-tech" use, rather than on a technology such as chaining or herbicide sprays.

Correlations between specific attitudes and beliefs are shown in Table 6. Two items, beliefs that riparian vegetation loss is a serious problem and attitudes toward a total ban on livestock grazing, had no significant correlations. Eighty percent of the remaining 45 pairs had attitude/belief correlations above $\mathrm{R}=.316$. All 36 significant correlations were in the expected direction; i.e., negative beliefs about range environments were associated with support for protective actions, and positive beliefs about rangeland conditions with support for traditional actions. Strong associations were found even where no causal connection between belief and attitude was readily discernible (e.g., "soil erosion is only a minor problem on federal rangelands" $x$ "endangered species laws should be set aside to preserve ranching jobs," $R=.499$ ).

Social-psychological theory suggests that attitudes toward a specific object (e.g., management of federal rangelands) are products of individuals' values and their beliefs about that object (Ajzen and Fishbein 1980). Values, defined as beliefs about desirable end-states and modes of conduct, tend to be more stable and enduring than beliefs or attitudes about specific objects (Rokeach 1979). In this study, values are reflected in the general attitude scales: the DOMINION scale reflects religious or materialist modes of conduct, the ETHICS scale reflects biocentrism and an end state of natural harmony that Rokeach (1979) called "world of beauty", and the SCIENCE scale reflects rationalist-technical modes of conduct.

Humans are motivated to maintain consistency in environmental attitudes (Heberlein 1981). However, as they learn more about an attitude object they are more likely to encounter conflicts between values. Then they must develop what Tetlock (1986) called integrative complexity or "tradeoff reasoning," which can lead to seemingly inconsistent attitudes. Tetlock (1986) offers the example of someone who values a "world of beauty" and a "comfortable life," and who experiences value conflict in forming an attitude toward the 
Table 6. Correlations between specific attitudes toward range management and beliefs about range environments.

\begin{tabular}{|c|c|c|c|c|c|c|}
\hline Attitude items & $\begin{array}{l}\text { Most range } \\
\text { is overgrazed }\end{array}$ & $\begin{array}{l}\text { Soil loss } \\
\text { is minor }\end{array}$ & $\begin{array}{l}\text { Wildlife is } \\
\text { increasing }\end{array}$ & $\begin{array}{l}\mathrm{H}_{2} \mathrm{O} \text { quality } \\
\text { is worsening }\end{array}$ & $\begin{array}{l}\text { Overgrazing } \\
\text { is reduced }\end{array}$ & $\begin{array}{l}\text { Riparian } \\
\text { veg. loss }\end{array}$ \\
\hline Priority to local cconomy & -.300 & $.400^{* 1}$ & $.461^{*}$ & -.241 & $.411^{*}$ & -.229 \\
\hline Ban livestock grazing & .221 & -.197 & -.221 & .207 & -.143 & -.015 \\
\hline Allow wilderness grazing & $-.371^{*}$ & $.423^{*}$ & $.467 *$ & $-.395 \%$ & $.405^{*}$ & .101 \\
\hline More protection for fish & $.424 *$ & $-.386 *$ & $-.395^{*}$ & $.415^{*}$ & -.306 & .015 \\
\hline More protection for rare plants & $.517 *$ & $-.413^{*}$ & $-.470 *$ & $.423 *$ & $-.368 *$ & -.040 \\
\hline More protection for wildlife & $.422 \%$ & -.292 & $-.378 *$ & $.632 \%$ & -.282 & .190 \\
\hline Ranchers should pay more & $.433 \%$ & -.301 & $-.364 *$ & $.347^{*}$ & -.237 & .040 \\
\hline
\end{tabular}

Asterisk indicate correlations explaining $>10 \%$ of variance in responses $(\mathrm{R}>3.316)$.

question: "Should public park lands be opened to mining and exploration in order to promote economic growth and prosperity?" That person may favor mining in parks for economic reasons while still holding environmentalist attitudes in a general sense.

Because integrative complexity is a product of increasingly complex chains of reasoning about an attitude object, we can expect correlations between general and specific attitudes to be larger when respondents have not thought much about the attitude object and so have not encountered value conflicts. Strong correlations between values and beliefs about rangelands would suggest that those beliefs are a product of general environmental values rather than of complex or sustained reasoning about rangelands-especially if the beliefs are not factually supported. Because attitudes are the products of an exceedingly complex information-processing system (the human brain), attitude/belief correlations above our alpha of .316 are relatively rare. The large number of highly significant correlations found here may be considered evidence that those attitudes and beliefs are products of a relatively simple cognitive structure with respect to rangelands. In other words, public attitudes toward specific range practices or policies are more likely to derive from people's general sense of the state of the environment and its proper stewardship than from any deeply rooted, highly reasoned beliefs or attitudes about rangelands.

Further evidence of this can be found in the rather monolithic structure of specific attitude/belief correlations. Respondents tended to believe either that rangeland conditions are uniformly bad or worsening and that protective actions are needed, or that rangeland conditions are uniformly good or improving and that traditional management is best. Nationally and in Oregon, there were more people in the former camp than the latter.

One belief and one attitude existed independently of other values, attitudes or beliefs measured here. Belief that riparian vegetation loss is a serious problem on rangelands was not strongly associated with any general or specific attitude. That may be because this was the only belief which was both demonstrably true and environmentally pessimistic, so that agreement with the item could result from either environmental ideology or knowledge about rangelands. Attitudes toward a total ban on livestock grazing likewise were not associated with any general environmental value or belief.
Environmentalism alone apparently cannot explain support of the "Cattle Free" movement, but must be considered along with other factors warranting further study, such as vegetarianism or inconvenience to recreation users.

\section{Conclusions and Implications}

This study examined variation in public attitudes and beliefs about federal rangelands and their management as a function of region, local importance of range uses, and environmental value/belief/attitude associations. We found relatively weak support for an East-West dichotomy on range issues, but much better support for a dichotomy between urbanized areas throughout the U.S. and those rural regions where rangelands are important to local economies. This could eventually translate to a loss of political power for range constituencies in the U.S. Senate if western urban interests assert their environmental views more strongly, but it is less likely to affect votes in the House of Representatives. We also found evidence that attitudes and beliefs about rangelands are typically part of a poorly developed cognitive structure rooted in simplistic, value-based ideas about the goodness or badness of range practices and conditions.

A fundamental presumption of survey research is that responses reflect pre-existing ideas that guide behavior. However, recent research suggests that when faced with questions about issues about which they have given little prior thought, respondents may construct answers on the spot (Tourangeau and Rasinski 1988). Measurement thus can create public opinion instead of capturing it (Simmons et al. 1993). This phenomenon might tempt range managers to simply disregard the results of surveys like this. However, Simmons et al. (1993) also found that respondents may be motivated to act consistently with their spuriously formed opinions. Given that possibility, the American political process makes it entirely possible for "created" public opinion to become public policy. For example, members of Congress whose districts don't contain rangelands may base votes on results of published opinion polls or informal surveys mailed to constituents. If our political system allows rangeland policy to be based on uninformed opinion, it becomes the responsibility of the range profession to create a better-informed public than now exists. 
An information campaign about range management should be just that: a systematic program to let the public know what rangelands are, how they function ecologically and socially, what problems they face as well as the values they support. Our results show that such efforts are as badly needed in the urban areas of the West as anywhere else. The temptation may be strong to try to induce change in attitudes through a slick, Madison Avenue-style approach, but the likelihood of quick success is not great because rangeland attitudes are strongly tied to values, and value-based attitudes can be highly resistant to change (Heberlein 1981). A more promising long-term strategy is to take advantage of the growing notoriety of rangelands-keeping range issues in the public eye whenever possible, so that a gradually better informed public begins to make the kind of "trade-off reasoning" that comes as greater understanding creates in people a need to resolve value conflicts.

\section{Literature Cited}

Ajzen, I. and M. Fishbein. 1980. Understanding attitudes and predicting social behavior. Prentice-Hall Inc., Englewood Cliffs, N.J.

Brown, G. and C. Harris. 1992. The USDA Forest Scrvice: toward the new resource management paradigm? Society \& Natur. Resour. 5:231-245.

Brunson, M.W. and J.J. Kennedy. 1995. Redefining multiple use: agency responses to changing social values. p. 186-195. In: R.L. Knight and S.F. Bates (eds.), A new century for natural resources management. Island Press, Washington, D.C.

Brunson, M.W. and B.S. Steel. 1994. National public attitudes toward federal rangeland management. Rangelands 16:77-81.

Buttel, F.H. 1987. New directions in environmental sociology. Ann. Rev. Sociol. 13:465-488.

Dillman, D.A. 1978. Mail and telephone surveys: the total design method. John Wiley \& Sons, N.Y.

Dunlap, R.E. 1992. American environmentalism: the US environmental movement. Taylor \& Francis, Philadelphia, Penn.

Dunlap, R.E. and K.D. Van Liere. 1978. The "new environmental paradigm": a proposed measuring instrument and preliminary results. J. Environ. Educ. 9(Summer):10-19.

Fortmann, L. and J. Kusel. 1990. New voices, old beliefs: forest environmentalism among new and long-standing rural residents. Rural Sociol. 55:214-232.

Graham, H. 1991. Americans report high levels of environmental concern, activity. Gallup Poll Monthly (April):6-12.

Heberlein, T.A. 1981. Environmental attitudes. Zeitschrift für Umweltpolitik 4:241-270.

Holechek, J.L., R.D. Pieper, and C.H. Herbel. 1989. Range management: principles and practices. Prentice Hall, Englewood Cliffs, N.J.

Noe, F.P. and W.E. Hammitt. 1992. Environmental attitudes and the personal relevance of management actions in a park setting. $J$. Environ. Manage. 35:205-216.

Pierce, J.C., N.C. Lovrich Jr., T. Tsurutani, and T. Abe. 1989. Public knowledge and environmental politics in Japan and in the United States. Westview, Boulder, Colo.

Rasker, R. 1993. Rural development, conservation, and public policy in the Greater Yellowstone Ecosystem. Society \& Natur. Resour. 6:109-126.

Rokeach, M. 1979. Understanding human values: Individual and societal. Free Press, N.Y.
Rudzitis, G. and H.E. Johansen. 1991. How important is wilderness? Results from a United States survey. Environ. Manage. 15:227-233.

Shindler, B., P. List, and B.S. Steel. 1993. Managing federal forests: public attitudes in Oregon and nationwide. J.Forest. 91:3642.

Simmons, C.J., B.A. Bickart, and J.G. Lynch Jr. 1993. Capturing and creating public opinion in survey research. J. Consumer Res. 20:316-329.

Steel, B.S., P. List and B. Shindler. 1994. Conflicting values about federal forests: a comparison of national and Oregon publics. Society \& Natur. Resour. 7:137-153.

Tetlock, P.E. 1986. A value pluralism model of ideological reasoning. J. Personality \& Soc. Psychol. 50:819-827.

Tourangeau, R. and K.A. Rasinski. 1988. Cognitive processes underlying context effects in attitude measurement. Psychol. Bull. 103:299-314. 